\title{
Overtreating Chronic Back Pain: Time to Back Off?
}

\author{
Richard A. Deyo, MD, MPH, Sohail K. Mirza, MD, MPH, Judith A. Turner, PhD, and \\ Brook I. Martin, MPH
}

Chronic back pain is among the most common patient complaints. Its prevalence and impact have spawned a rapidly expanding range of tests and treatments. Some of these have become widely used for indications that are not well validated, leading to uncertainty about efficacy and safety, increasing complication rates, and marketing abuses. Recent studies document a 629\% increase in Medicare expenditures for epidural steroid injections; a $423 \%$ increase in expenditures for opioids for back pain; a 307\% increase in the number of lumbar magnetic resonance images among Medicare beneficiaries; and a $220 \%$ increase in spinal fusion surgery rates. The limited studies available suggest that these increases have not been accompanied by population-level improvements in patient outcomes or disability rates. We suggest a need for a better understanding of the basic science of pain mechanisms, more rigorous and independent trials of many treatments, a stronger regulatory stance toward approval and post-marketing surveillance of new drugs and devices for chronic pain, and a chronic disease model for managing chronic back pain. (J Am Board Fam Med 2009;22:62-68.)

Pain complaints are a leading reason for medical visits. ${ }^{1}$ The most common pain complaints are musculoskeletal, and back pain is the most common of these. The prevalence and impact of back pain have led to an expanding array of tests and treatments, including injections, surgical procedures, implantable devices, and medications. Each is valuable for some patients, but use may be expanding beyond scientifically validated indications, ${ }^{2-4}$ driven by professional concern, patient advocacy, marketing, and the media.

More tests and treatments do not simply reflect a greater incidence of back pain. The proportion of office visits attributed to back pain has changed

This article was externally peer reviewed.

Submitted 15 May 2008; revised 23 July 2008; accepted 29 July 2008 .

From the Department of Medicine, Oregon Health and Science University, Portland (RAD) and the Departments of Orthopaedics (SKM, BIM) and Psychiatry (JAT), University of Washington, Seattle.

Funding: Supported in part by grants \# 5P60-AR48093 and \#5K23AR48979 from the National Institute of Arthritis, Musculoskeletal and Skin Diseases.

Conflict of interest: The research program of Drs. Deyo and Mirza has benefited from a gift to the University of Washington from Synthes, a surgical device manufacturer. They have not received any personal financial support from this source. Mr. Martin has received partial salary support from this source. Dr. Turner has no conflicts to declare.

Corresponding author: Richard A. Deyo, MD, MPH, Family Medicine, Mail Code FM, 3181 SW Sam Jackson Park Rd., Portland, OR 97239-3098 (E-mail: deyor@ohsu.edu). little since $1990 .{ }^{5}$ In recent National Health Interview Surveys, approximately a quarter of US adults reported back pain during the past 3 months, broadly consistent with previous surveys. ${ }^{5}$

There are important implications of expanded testing and treatment for back pain. Innovation has often outpaced clinical science, leaving uncertainty about the efficacy and safety of many common treatments. Complications and even deaths related to pain management are increasing. ${ }^{6,7}$ Despite uncertainties, manufacturers aggressively promote new drugs and devices. However, trust in the science supporting these products is eroded by revelations of misleading advertising, ${ }^{8}$ allegations of kickbacks to physicians, ${ }^{9}$ and major investments by surgeons in the products they are investigating. ${ }^{10}$

We focus here on common management decisions in primary care related to imaging, medication, and referral for injections or surgery. Our goal was not to conduct systematic reviews of each of these or to provide a treatment guide, but to summarize data on recent trends, highlight certain risks, provide conclusions from systematic reviews on efficacy, and comment on practice patterns.

\section{Imaging for Low Back Pain}

Despite guidelines recommending parsimonious imaging, use of lumbar magnetic resonance imag- 
a Lumbar spine MR imaging, Medicare

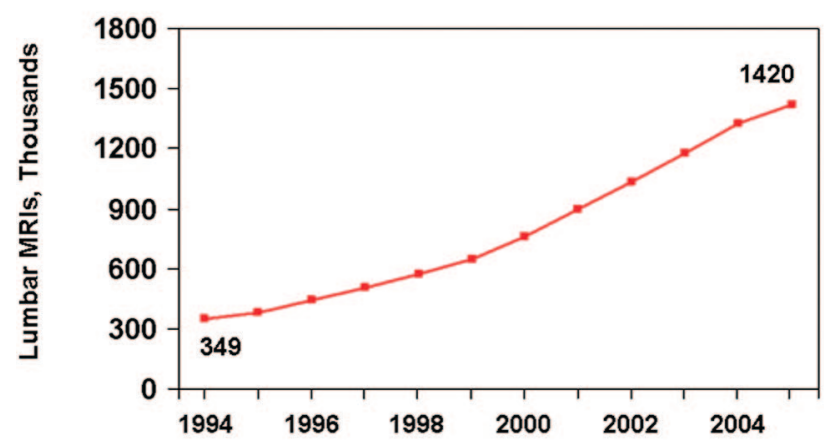

c Lumbosacral injection rates, Medicare

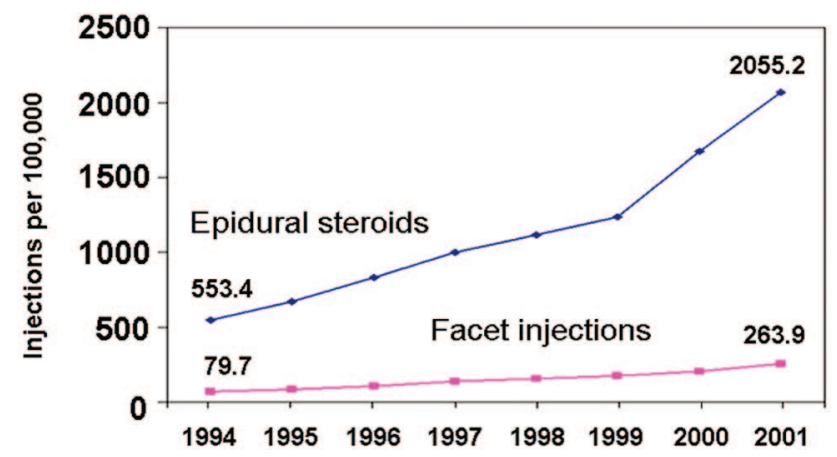

b Opioid analgesic prescriptions for spine problems

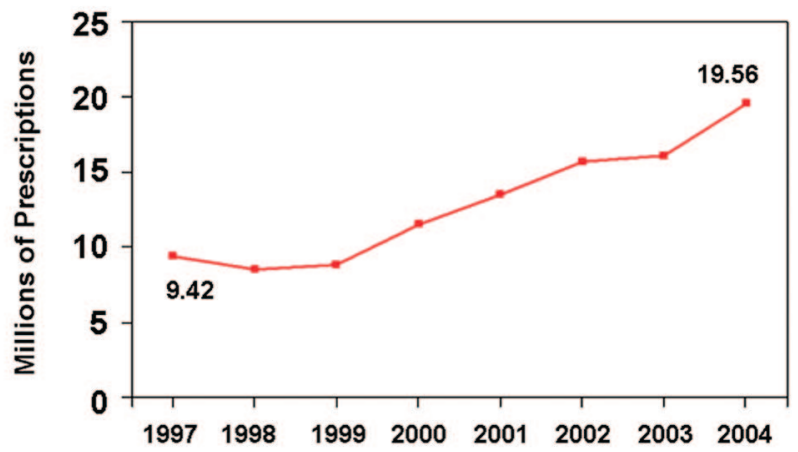

d Lumbar fusion rates, degenerative spine conditions

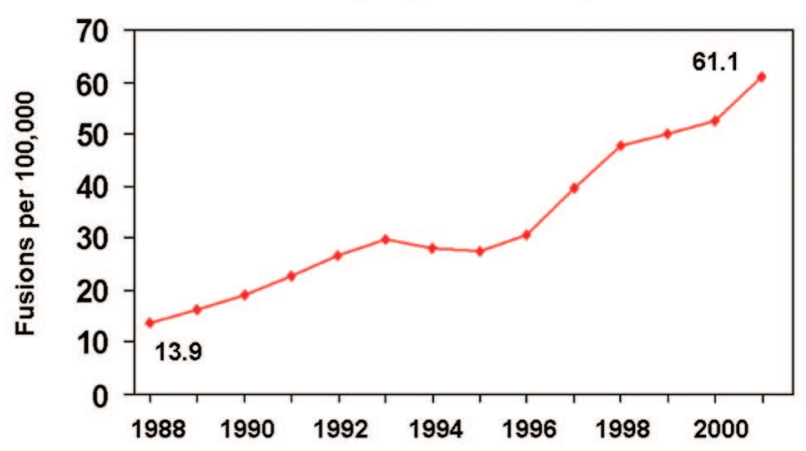

Figure 1. Increases in the use of various services for low back pain. A: Lumbar spine magnetic resonance imaging (CPT codes 72148, 72149, 72158); numbers of scans among Medicare beneficiaries from Part B claims. B: Numbers of opioid prescriptions for spine conditions, national data from the Medical Expenditure Panel Survey. ${ }^{11}$ C: Rates of lumbosacral injections in the Medicare population, age- and sex-adjusted. (Data are from reference 2, adapted with permission.) D: Lumbar spine fusion rates for degenerative conditions, age- and sex-adjusted, National Inpatient Sample. (From reference 3, reproduced with permission.)

ing (MRI) increased in the Medicare population by $307 \%$ during a recent 12-year interval (Figure 1A; previously unpublished data). Others have described rapid increases in spine imaging and for imaging procedures in general. ${ }^{11,12}$ Spine imaging rates vary dramatically across geographic regions, ${ }^{13}$ and surgery rates are highest where imaging rates are highest. ${ }^{13}$ When judged against guidelines, one-third to two-thirds of spinal computed tomography imaging and MRI may be inappropriate. ${ }^{14-16}$ Many factors probably underlie the growth of imaging, including patient demand, ${ }^{17}$ the compelling nature of visual evidence, ${ }^{18}$ fear of lawsuits, and financial incentives. ${ }^{19}$

One problem with inappropriate imaging is that it may result in findings that are irrelevant but alarming. Positive findings, such as herniated disks, are common in asymptomatic people..$^{20-22}$ In a randomized trial $^{23}$ there was a trend toward more surgery and higher costs among patients receiving early spinal MRI than those receiving plain films, but no better clinical outcomes. Six other randomized trials, involving a total of 1804 patients from primary care without features suggesting a serious underlying disease, compared some form of lumbar spine imaging with none. ${ }^{24-29}$ In these studies, imaging was not associated with an advantage in subsequent pain, function, quality of life, or overall improvement.

Based on an extensive systematic review, the joint guidelines of the American College of Physicians and the American Pain Society explicitly recommend against routine imaging in patients with nonspecific low back pain (ie, no severe or progressive neurologic deficits or evidence of serious underlying conditions). ${ }^{30}$

\section{Opioid Analgesics}

Prescription opioid use is steadily increasing, overall and for musculoskeletal conditions in particu- 
lar. ${ }^{4,71-35}$ Among patients with spinal disorders, the National Medical Expenditure Panel Survey showed a $108 \%$ increase in opioid prescriptions from 1997 through 2004 (Figure 1B). The combination of increasing use and higher drug prices resulted in a $423 \%$ inflation-adjusted increase in expenditures. ${ }^{31}$ These trends have been driven at least partly by concern for the under-treatment of pain in the past, especially among patients with cancer or terminal illness.

Emergency department reports of opioid overdose parallel the numbers of prescriptions. ${ }^{4}$ Deaths related to prescription opioids have increased; by 2002 there were 4451 deaths related to opioid analgesics, more than the combined total involving cocaine or heroin alone. ${ }^{7}$ Diversion of prescription opioids is increasingly common, with broad societal impacts. $^{4,36,37}$

Unlike advanced cancer or postoperative pain, chronic back pain often persists for years or decades. In this setting, the efficacy and safety of long-term opioid use remain controversial. Nonetheless, more than half of "regular" prescription opioid users have back pain. ${ }^{38}$ A systematic review concluded that, for chronic back pain, short-term advantages over nonopioid analgesics were modest, whereas data beyond 16 weeks were unavailable. ${ }^{39}$

The Cochrane Collaboration review of opioids for chronic low back pain similarly concluded that, "Despite concerns surrounding the use of opioids for long-term management of chronic [low back pain], there remain few high-quality trials assessing their efficacy ... Based on our results, the benefit of opioids in clinical practice for the long-term management of chronic [low back pain] remains questionable. ${ }^{40}$ In population-based studies, many patients receiving opioids for noncancer pain have persistent high levels of pain and poor quality of life. $^{41}$

Ironically, patients with major depression and other psychiatric disorders are more likely than others to initiate and to continue opioid therapy, ${ }^{42}$ yet they also are more likely to misuse medication $^{43,44}$ and may be less likely to experience analgesic benefit. ${ }^{45}$ Although depression and other psychiatric disorders are common among patients with chronic back pain, ${ }^{42,46-48}$ patients with such disorders are commonly excluded from trials of opioid therapy, ${ }^{42}$ which raises questions about the generalizability of efficacy studies to routine practice.
Some adverse effects of opioid use may be underappreciated, including hyperalgesia, ${ }^{49,50}$ which may result from changes in the brain, spinal cord, and peripheral nerves. ${ }^{51-53}$ In short, opioid use may paradoxically increase sensitivity to pain. Hypogonadism is another underappreciated consequence of chronic use, resulting in reduced testosterone levels, diminished libido, and erectile dysfunction. $^{54-56}$

The American College of Physicians/American Pain Society guidelines conclude that "opioid analgesics are an option when used judiciously in patients with acute or chronic low back pain who have severe, disabling pain that is not controlled (or is unlikely to be controlled) with acetaminophen and nonsteroidal anti-inflammatory drugs. Because of substantial risks ... potential benefits and harms of opioid analgesics should be carefully weighed before starting therapy. Failure to respond to a time-limited course of opioids should lead to reassessment and consideration of alternative therapies or referral for further evaluation." 30

\section{Spinal Injections}

The efficacy of spinal injections is limited. Epidural corticosteroid injections may offer temporary relief of sciatica, but both European and American guidelines, based on systematic reviews, conclude they do not reduce the rate of subsequent surgery. ${ }^{57,58}$ This conclusion is based on multiple randomized trials comparing epidural steroid injections with placebo injections, and monitoring of subsequent surgery rates. ${ }^{59-62}$ Facet joint injections with corticosteroids seem no more effective than saline injections. $^{57,63}$

Despite the limited benefit of epidural injections, Medicare claims showed a $271 \%$ increase during a recent 7-year interval (Figure 1C). ${ }^{2}$ Facet joint injections increased $231 \% .^{2}$ Earlier Medicare claims analyses also demonstrated rapid increases in spinal injection rates. ${ }^{12,64}$ For patients with axial back pain without sciatica there is no evidence of benefit from spinal injections ${ }^{57}$; however, many injections given to patients in the Medicare population seemed to be for axial back pain alone. ${ }^{2}$

Charges per injection rose $100 \%$ during the past decade (after inflation), and the combination of increasing rates and charges resulted in a $629 \%$ increase in fees for spinal injections. ${ }^{2}$ During this time, the Medicare population increased by only $12 \%$. 


\section{Spine Surgery}

Although spine fusion surgery has a well-established role in treating fractures and deformities, 4 randomized trials indicate that its benefit is more limited when treating degenerative discs with back pain alone (no sciatica). ${ }^{65}$ Despite no specific concurrent reports of clarified indications or improved efficacy, there was a $220 \%$ increase in the rate of lumbar spine fusion surgery from 1990 to 2001 in the United States (Figure 1D). ${ }^{3}$ The rise accelerated after 1996 when the fusion cage, a new type of surgical implant, was approved. ${ }^{3}$ Their promotion may have contributed to both the rise in fusion rates and increased use of implants. In the last 5 years of the 1990s, Medicare claims demonstrated a $40 \%$ increase in spine surgery rates, a $70 \%$ increase in fusion surgery rates, and a $100 \%$ increase in use of implants. ${ }^{66}$

Higher spine surgery rates are sometimes associated with worse outcomes. In the state of Maine, the best surgical outcomes occurred where surgery rates were lowest; the worst results occurred in areas where rates were highest. ${ }^{67}$ Multiple randomized trials suggest that adding surgical implants to bone grafting slightly improves rates of solid bone fusion but may not improve pain or function. ${ }^{68-70}$ Implants increase the risk of nerve injury, blood loss, overall complications, operative time, and repeat surgery. ${ }^{68,69}$ In a large study of injured workers, the rapid increase in the use of intervertebral fusion cages after 1996 was associated with increased complications but not with improved disability or reoperation rates. ${ }^{71} \mathrm{We}$ recently found that reoperation rates after initial spine surgery were higher in the late 1990s than earlier in the decade, despite greater use of fusion procedures and implants. ${ }^{6}$

\section{Are We Improving Outcomes?}

Jumps in imaging, opioid prescriptions, injections, and fusion surgery might be justified if there were substantial improvements in patient outcomes. Even in successful trials of these treatments, though, most patients continue to experience some pain and dysfunction. Population-level data on back-related dysfunction are sparse. However, despite a rise in costs related to spine problems, the US Medical Expenditure Panel Survey showed that self-reported functional limitations, mental health, work limitations, and social limitations were worse

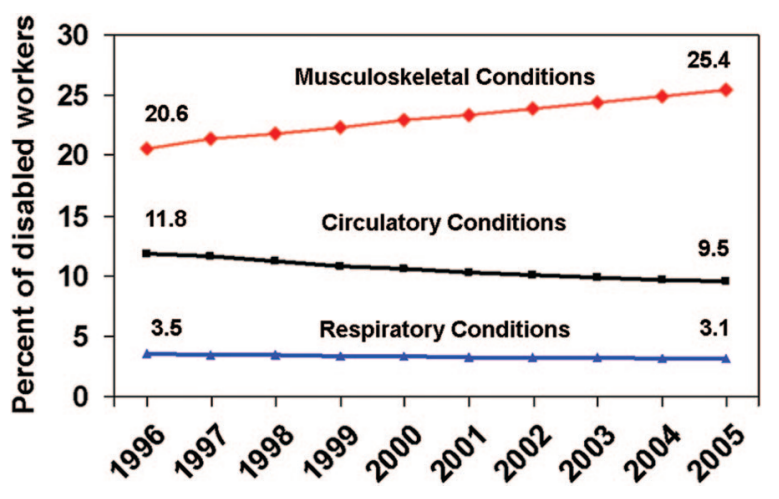

Figure 2. Percentage of individuals with permanent work disability (Social Security Disability Income beneficiaries) disabled by various medical conditions. (Data are from reference 24.)

among people reporting such problems in 2005 than in $1997 .^{31}$

Furthermore, Social Security Disability Insurance statistics suggest that disability from musculoskeletal disorders is rising, not falling. Work disability attributed to musculoskeletal disorders, much of which is back pain, increased from $20.6 \%$ of beneficiaries in 1996 to $25.4 \%$ in 2005 (Figure 2). ${ }^{72}$ This was not a growing proportion of a shrinking pie; the number of Social Security Disability Insurance recipients increased over these years. Although it is unclear exactly what proportion of musculoskeletal disability is from back pain, the data suggest that current management of musculoskeletal pain is not highly successful. In contrast, for conditions where effective prevention and treatment have emerged, such as circulatory and respiratory diseases, the proportion of disabled beneficiaries fell.

\section{Implications and Possible Responses}

Prescribing yet more imaging, opioids, injections, and operations is not likely to improve outcomes for patients with chronic back pain. We must rethink chronic back pain at fundamental levels. Our understanding of chronic back pain mechanisms remains rudimentary, including our knowledge of spinal biology, central nervous system processing, genetic factors, and psychosocial and environmental influences. Greater investment is needed in this basic science research.

Clinicians may often be applying an acute care model to a chronic condition. There are no "magic bullets" for chronic back pain, and expecting a cure from a drug, injection, or operation is generally wish- 
ful thinking. These approaches risk overlooking the psychosocial, occupational, and lifestyle dimensions of chronic pain. Although evidence remains incomplete and the magnitude of benefits may be modest, data support the benefits of interventions that promote patient involvement and activity (eg, graded exercise programs and group support). ${ }^{73-77}$ These therapies also have the advantage of being low risk.

A "chronic care model" would acknowledge that chronic back pain, like diabetes or asthma, is a condition we can treat but rarely cure. As with other chronic conditions, care of chronic back pain may benefit from sustained commitment from health care providers; involvement of patients as partners in their care; education in self-care strategies; coordination of care; and involvement of community resources to promote exercise, provide social support, and facilitate a return to work. ${ }^{78,79}$ Patients need realistic expectations despite product marketing, media reports, and medical rhetoric that promise a pain-free life.

Each treatment and test discussed here has a role in managing back pain, but the evidence base for judicious use remains inadequate. Greater federal involvement in research about therapies and devices may be necessary to provide independent assessments. Initiatives in comparative effectiveness research would be particularly welcome in this regard. Research emphasis should shift from studying fine points of procedural technique to determining who benefits most. Instead of measuring only technical success (solid bony fusion or properly placed injection), research should clarify a treatment's safety and its effects on pain, function, and return to work. Serious complications and unclear benefits highlight the need for more rigorous approval and better post-marketing surveillance of both drugs and devices for treating pain. Without stronger evidence insurers may reasonably question coverage of newer drugs, devices, and procedures. ${ }^{80} \mathrm{In}$ the meantime, we should fully inform patients about available treatment options, including the best available evidence for effectiveness, uncertainties, and risks, and encourage them to play an expanded role in therapeutic decision making. ${ }^{77}$

\section{References}

1. Raofi S, Schappert SM. Medication therapy in ambulatory medical care: United States, 2003-04. Vital Health Stat 13 2006;13:1-40.

2. Friedly J, Chan L, Deyo R. Increases in lumbosacral injections in the Medicare population: 1994-2001. Spine 2007;32:1754-60.

3. Deyo RA, Gray DT, Kreuter W, Mirza S, Martin BI. United States trends in lumbar fusion surgery for degenerative conditions. Spine 2005;30:1441-5.

4. Compton WM, Volkow ND. Major increases in opioid analgesic abuse in the United States: concerns and strategies. Drug Alcohol Depend 2006;81:103-7.

5. Deyo RA, Mirza SK, Martin BI. Back pain prevalence and visit rates: estimates from US national surveys, 2002. Spine 2006;31:2724-7.

6. Martin BI, Mirza SK, Comstock BA, Gray DT, Kreuter W, Deyo RA. Are lumbar spine reoperation rates falling with greater use of fusion surgery and new surgical technology? Spine 2007;32:2119-26.

7. Paulozzi LJ, Budnitz DS, Xi Y. Increasing deaths from opioid analgesics in the United States. Pharmacoepidemiol Drug Saf 2006;15:618-27.

8. Meier B. Three officials are sentenced in case involving OxyContin. The New York Times, July 21, 2007;C4.

9. Abelson R. Medtronic will settle accusations on kickbacks. The New York Times, July 19, 2006;C4.

10. Abelson R. Financial ties are cited as issue in spine study. The New York Times, January 30, 2008.

11. Mitchell JM. Utilization trends for advanced imaging procedures: evidence from individuals with private insurance coverage in California. Medical Care 2008;46:460-6

12. Weiner DK, Kim YS, Bonino P, Wang T. Low back pain in older adults: are we utilizing healthcare resources wisely? Pain Med 2006;7:143-50.

13. Lurie JD, Birkmeyer NJ, Weinstein JN. Rates of advanced spinal imaging and spine surgery. Spine 2003;28:616-20.

14. Swedlow A, Johnson G, Smithline N, Milstein A. Increased costs and rates of use in the California workers' compensation system as a result of self-referral by physicians. N Engl J Med 1992;327:1502-6.

15. Rao JK, Kroenke K, Mihaliak KA, Eckert GJ, Weinberger M. Can guidelines impact the ordering of magneteic resonsance imaging studies by primary care providers for low back pain? Am J Manag Care 2002;8:27-35.

16. Schroth WS, Schectman JM, Elinsky EG, Panagides JC. Utilization of medical services for the treatment of acute low back pain: conformance with clinical guidelines. J Gen Intern Med 1992;7:486-91.

17. McPhillips-Tangum CA, Cherkin DC, Rhodes LA, Markham C. Reasons for repeated medical visits among patients with chronic back pain. J Gen Intern Med 1998;13:289-95.

18. Rhodes LA, McPhillips-Tangum CA, Markham C, Klenk R. The power of the visible: the meaning of diagnostic tests in chronic back pain. Soc Science Med 1999;48:1189-203.

19. Mitchell JM. Do financial incentives linked to own- 
ership of specialty hospitals affect physicians' practice patterns? Medical Care 2008;46:732-7.

20. Jensen MC, Brant-Zawadzki MN, Obuchowski N, Modic MT, Malkasian D, Ross JS. Magnetic resonance imaging of the lumbar spine in people without back pain. N Engl J Med 1994;331:69-73.

21. Boden SD, Davis DO, Dina TS, Patronas NJ, Wiesel SW. Abnormal magnetic-resonance scans of the lumbar spine in asymptomatic subjects. A prospective investigation. J Bone Joint Surg 1990;72:403-8.

22. Jarvik JJ, Hollingworth W, Heagerty P, Haynor DR, Deyo RA. The longitudinal assessment of Imaging and disability of the back (LAIDBack) Study: baseline data. Spine 2001;26:1158-66.

23. Jarvik JG, Hollingworth W, Martin B, et al. Rapid magnetic resonance imaging vs radiographs for patients with low back pain; a randomized controlled trial. JAMA 2003;289:2810-8.

24. Djais N, Kalim H. The role of lumbar spine radiography in the outcomes of patients with simple acute low back pain. APLAR Journal of Rheumatology 2005;8:45-50.

25. Gilbert FJ, Grant AM, Gillan MG, et al. Low back pain: influence of early MR imaging or CT on treatment and outcome-multicenter randomized trial. Radiology 2004;231:343-51.

26. Kendrick D, Fielding K, Bentley E, Kerslake R, Miller P, Pringle M. Radiography of the lumbar spine in primary care patients with low back pain: randomised controlled trial. BMJ 2001;322:400-5.

27. Kerry S, Hilton S, Dundas D, Rink E, Oakeshott P. Radiography for low back pain: a randomised controlled trial and observational study in primary care. Br J Gen Pract 2002;52:469-74.

28. Modic MT, Obuchowski NA, Ross JS, et al. Acute low back pain and radiculopathy: MR imaging findings and their prognostic role and effect on outcome. Radiology 2005;237:597-604.

29. Deyo RA, Diehl AK, Rosenthal M. Reducing roentgenography use. Can patient expectations be altered? Arch Intern Med 1987;147:141-5.

30. Chou R, Qaseem A, Snow V, Casey D, Cross JT, Shekelle P, Owens DK. Diagnosis and treatment of low back pain: a joint clinical practice guideline from the American College of Physicians and the American Pain Society. Ann Intern Med 2007;147:478-91.

31. Martin BI, Deyo RA, Mirza SK, Turner JA, Comstock BA, Hollingworth W, Sullivan SD. Expenditures and health status among adults with back and neck problems. JAMA 2008;299:656-64.

32. Caudill-Slosberg MA, Schwartz LM, Woloshin S. Office visits and analgesic prescriptions for musculoskeletal pain in US: 1980 vs. 2000. Pain 2004;109: 514-9.

33. Franklin GM, Mai J, Wickizer T, Turner JA, Fulton-Kehoe D, Grant L. Opioid dosing trends and mortality in Washington State workers' compensation, 1996-2002. Am J Ind Med 2005;48:91-9.
34. Luo X, Pietrobon R, Hey L. Patterns and trends in opioid use among individuals with back pain in the United States. Spine 2004;29:884-91.

35. Zerzan JT, Morden NE, Soumerai S, et al. Trends and geographic variation of opiate medication use in state Medicaid fee-for-service programs, 1996 to 2002. Med Care 2006;44:1005-10.

36. Katz DA, Hays LR. Adolescent OxyContin abuse. J Am Acad Child Adolesc Psych 2004;43:231-4.

37. Friedman RA. The changing face of teenage drug abuse-the trend toward prescription drugs. N Engl J Med 2006;354:1448-50.

38. Sullivan MD, Edlund MJ, Steffick D, Unutzer J. Regular use of prescribed opioids: association with common psychiatric disorders. Pain 2005;119:95-103.

39. Martell BA, O'Connor PG, Kerns RD, Becker WC, Morales KH, Kosten TR, Fiellin DA. Systematic review: opioid treatment for chronic back pain: prevalence, efficacy, and association with addiction. Ann Intern Med 2007;146:116-27.

40. Deshpande A, Furlan A, Maillis-Gagnon A, Atlas S, Turk D. Opioids for chronic low-back pain. Cochrane Database Syst Rev 2007;18:CD004959.

41. Eriksen J, Sjogren P, Bruera E, Ekholm O, Rasmussen NK. Critical issues on opioids in chronic noncancer pain: an epidemiological study. Pain 2006; 125:172-9.

42. Sullivan MD, Edlund MJ, Zhang L, Unutzer J, Wells KB. Association between mental health disorders, problem drug use, and regular prescription opioid use. Arch Intern Med 2006;166:2087-93.

43. Wasan AD, Butler SF, Budman SH, Benoit C, Fernandez K, Jamison RN. Psychiatric history and psychologic adjustment as risk factors for aberrant drugrelated behavior among patients with chronic pain. Clin J Pain 2007;23:307-15.

44. Edlund MJ, Steffick D, Hudson T, Harris KM, Sullivan $M$. Rick factors for clinically recognized opioid abuse and dependence among veterans using opioids for chronic non-cancer pain. Pain 2007;129:355-62.

45. Wasan AD, Davar G, Jamison R. The association between negative affect and opioid analgesia in patients with discogenic low back pain. Pain 2005;117: 450-61.

46. Bair MJ, Robinson RL, Katon W, Kroenke K. Depression and pain comorbidity: a literature review. Arch Intern Med 2003;163:2433-45.

47. Demyttenaere K, Bruffaerts R, Lee S, et al. Mental disorders among persons with chronic back or neck pain: results from the World Mental Health Surveys. Pain 2007;129:332-42.

48. Carragee EJ. Psychological and functional profiles in select subjects with low back pain. Spine J 2001;1: 198-204.

49. Chu, LF, Clark DJ, Angst MS. Opioid tolerance and hyperalgesia in chronic pain patients after one month of oral morphine therapy: a preliminary prospective study. J Pain 2006;7:43-8. 
50. Chang G, Chen L, Mao J. Opioid tolerance and hyperalgesia. Med Clin North Am 2007;91:199-211.

51. Melzack R, Coderre TJ, Katz J, Vaccarino AL. Central Neuroplasticity and pathological pain. Ann N Y Acad Sci 2001;933:157-74.

52. Chu LF, Angst MS, Clark D. Opioid-induced hyperalgesia in humans: molecular mechanisms and clinical considerations. Clin J Pain 2008;24:479-96.

53. Ossipov MH, Lai J, King T, Vanderah TW, Porreca F. Underlying mechanisms of pronociceptive consequences of prolonged morphine exposure. Biopolymers 2005;80:319-24.

54. Daniell HW. Hypogonadism in men consuming sustained-action oral opioids. J Pain 2002;3:377-84.

55. Roberts LJ, Finch PM, Pullan PT, Bhagat CI, Price LM. Sex hormone suppression by intrathecal opioids: a prospective study. Clin J Pain 2002;18:144-8.

56. Rajagopal A, Vassilopoulou-Sellin R, Palmer JL, Kaur G, Bruera E. Symptomatic hypogonadism in male survivors of cancer with chronic exposure to opioids. Cancer 2004;100:851-8.

57. Airaksinen O, Brox JI, Cedraschi C, et al. European guidelines for the management of chronic nonspecific low back pain. Eur Spine J 2006;15(Suppl 2): S192-S300.

58. Armon C, Argoff CE, Samuels J, Backonja M. Assessment: use of epidural steroid injections to treat radicular lumbosacral pain. Report of the Therapeutics and Technology Assessment Subcommittee of the American Academy of Neurology. Neurology 2007;68:723-9.

59. Arden NK, Price C, Reading I, et al. A multicentre randomized controlled trial of epidural corticosteroid injections for sciatica: the WEST study. Rheumatology 2005;44:1399-406.

60. Carette S, Leclaire R, Marcoux S, et al. Epidural corticosteroid injections for sciatica due to herniated nucleus pulposus. N Engl J Med 1997;336:1634-40.

61. Cuckler JM, Bernini PA, Wiesel SW, Booth RE, Rothman RH, Pickens GT. The use of epidural steroids in the treatment of lumbar radicular pain. A prospective, randomized, double-blind study. J Bone Joint Surg Am 1985;67:63-6.

62. Wilson-MacDonald, Burt G, Griffin D, Glynn C. Epidural steroid injection for nerve root compression. J Bone Joint Surg Br 2005;87:352-5.

63. Chou R, Rosenquist R, Loeser J. ACP-APS guidelines for surgical and interventional procedures for chronic low back pain. Presented at Symposium 312 of the American Pain Society 27th Annual Scientific Meeting, Tampa, Florida, May 8, 2008.

64. Carrino JA, Morrison WB, Parker L, Schweitzer ME, Levin DC, Sunshine JH. Spinal injection procedures: volume, provider distribution and reimbursement in the US Medicare population from 1993 to 1999. Radiology 2002;225:723-9.

65. Mirza SK, Deyo RA. Systematic review of randomized trials comparing lumbar fusion surgery to non- operative care for treatment of chronic back pain. Spine 2007;32:816-23.

66. Lurie JD, Weinstein JN. Shared decision-making and the orthopaedic workforce. Clin Orthop 2001; 385:68-75.

67. Keller RB, Atlas SJ, Soule DN, Singer DE, Deyo RA. Relationship between rates and outcomes of operative treatment for lumbar disc herniation and spinal stenosis. J Bone Joint Surg 1999;81:752-62.

68. Deyo RA, Nachemson A, Mirza SK. Spinal-fusion surgery: the case for restraint. N Engl J Med 2004; 350:722-6.

69. Fritzell P, Hagg O, Nordwall A. Complications in lumbar fusion surgery for chronic low back pain: comparison of three surgical techniques used in a prospective randomized study. A report from the Swedish Lumbar Spine Study Group. Eur Spine J 2003;12:178-89.

70. Thomsen K, Christensen FB, Eiskjaer SP, Hansen ES, Fruensgaard S, Bunger CE. The effect of pedicle screw instrumentation on functional outcome and fusion rates in posterolateral lumbar spinal fusion: a prospective, randomized clinical study. Spine 1997;22:2813-22.

71. Maghout-Juratli S, Franklin GM, Mirza SK, Wickizer TM, Fulton-Kehoe D. Lumbar fusion outcomes in Washington State workers' compensation. Spine 2006;31:2715-23.

72. Social Security Administration Office of Policy. Annual Statistical Report on the Social Security Disability Insurance Program, 2005. SSA publication no. 13-11826. Washington, DC: Social Security Administration; 2006.

73. Hayden JA, van Tulder MW, Malmivaara AV, Koes BW. Meta-analysis: exercise therapy for nonspecific low back pain. Ann Intern Med 2005;142:765-75.

74. Lorig KR, Laurent DD, Deyo RA, Marnell ME, Minor MA, Ritter PL. Can a back pain e-mail discussion group improve health status and lower health care costs? A randomized study. Arch Intern Med 2002;162:792-6.

75. Hoffman BM, Papas RK, Chatkoff DK, Kerns RD. Meta-analysis of psychological interventions for chronic low back pain. Health Psychol 2007;26:1-9.

76. Staal JB, Hiobil H, Twisk JW, Smid T, Koke AJ, van Mechelen W. Graded activity for low back pain in occupational health care: a randomized, controlled trial. Ann Intern Med 2004;140:77-84.

77. Deyo RA. A key medical decision maker: the patient. BMJ 2001;323:466-7.

78. Bodenheimer T, Wagner EH, Grumbach K. Improving primary care for patients with chronic illness. JAMA 2002;288:1775-9.

79. Bodenheimer T, Wagner EH, Grumbach K. Improving primary care for patients with chronic illness: the chronic care model, part 2. JAMA 2002; 288:1909-14.

80. Feder BJ. Medicare plans to deny coverage of artificial disks. The New York Times, May 26, 2007;C9. 